\title{
Effects of maternal exposure to social stress during pregnancy: consequences for mother and offspring
}

\author{
Paula J Brunton \\ Division of Neurobiology, The Roslin Institute and R(D)SVS, University of Edinburgh, Easter Bush Campus, \\ Midlothian, Scotland EH25 9RG, UK \\ Correspondence should be addressed to PJ Brunton; Email: p.j.brunton@ed.ac.uk
}

\begin{abstract}
A suboptimal in utero environment, for example, as a result of maternal stress, can have detrimental effects on the pregnancy and long-term adverse 'programming' effects on the offspring. This article focuses on the effects of prenatal social stress on the mother, her pregnancy and the offspring, since these issues have ethological relevance in both animals and humans. The consequences of social stress exposure depend on when during pregnancy the stress occurs, and many of the effects on the offspring are sex specific. Social stress during early pregnancy tends to result in pregnancy loss, whereas stress exposure later in pregnancy, when the mother has already invested considerable resources in the foetuses, results in programmed offspring of low birth weight: a risk factor for various adulthood diseases. Neuroendocrine and behavioural responses to stress in the offspring are particularly sensitive to foetal programming by prenatal stress, indicated by enhanced hypothalamo-pituitary-adrenal (HPA) axis responses and increased anxiety behaviour, which result from permanent changes in the offspring's brain. The dysregulation of HPA axis function may also interfere with other systems, for example, the hypothalamic-pituitary-gonadal axis, as there is evidence for alterations in steroidogenesis, reproductive potential and impaired reproductive/social behaviours in prenatally stressed offspring. Prenatal social stress also programmes future maternal behaviour, highlighting the potential for negative phenotypes to be transmitted to future generations. The possible mechanisms through which maternal stress during pregnancy is transmitted to the foetuses and the foetal brain is programmed by prenatal stress and the potential to overwrite programming of the offspring are discussed.

Reproduction (2013) 146 R175-R189
\end{abstract}

\section{Introduction}

Adverse early-life experiences, including maternal exposure to stress during pregnancy, can 'programme' persistent changes in several physiological systems and behaviours, probably via epigenetic mechanisms (Meaney et al. 2007). In rodents, prenatal stress is associated with negative pregnancy outcomes such as low birth weight, reduced litter sizes and lower survival rates (de Catanzaro 1988, Pratt \& Lisk 1991, Brunton \& Russell 2010, Paris et al. 2011), and in the adult offspring, it is associated with heightened anxiety (Fride \& Weinstock 1988, Vallee et al. 1997, Fan et al. 2009, Brunton \& Russell 2010), enhanced or prolonged hypothalamo-pituitary-adrenal (HPA) axis (Fig. 1) responses to acute stress (Takahashi \& Kalin 1991, Weinstock et al. 1992, McCormick et al. 1995, Koenig et al. 2005, Fan et al. 2009, Brunton \& Russell 2010), hypertension (Igosheva et al. 2004), impaired glucose homoeostasis (Brunton et al. 2013), insulin resistance (Nilsson et al. 2001), diet-induced obesity (Nilsson et al. 2001, Tamashiro et al. 2009), impaired neural development (Lemaire et al. 2000), cognitive deficits
(Lemaire et al. 2000, Paris \& Frye 2011, Paris et al. 2011), and abnormal social (Patin et al. 2005, Lee et al. 2007) and reproductive behaviours (Holson et al. 1995, Frye \& Orecki 2002).

These programming effects may be considered to be predictive adaptations that inform the offspring of an unpredictable postnatal environment and permit the foetus to adapt in order to cope with unfavourable conditions (Gluckman \& Hanson 2004). For example, enhanced behavioural and neuroendocrine responses to stress may reflect greater vigilance to environmental threats, which may promote survival even if this has a long-term cost (McEwen 2008) that reduces life expectancy (Claessens et al. 2011). However, often this programming is maladaptive, particularly when there is a mismatch between the predicted and the actual postnatal environment, and this can increase the susceptibility of the offspring to various diseases, for example, cardiovascular disease, diabetes mellitus type 2, obesity, cognitive decline and mood disorders (Seckl \& Holmes 2007).

The majority of studies investigating the effects of prenatal stress on the offspring have been carried 


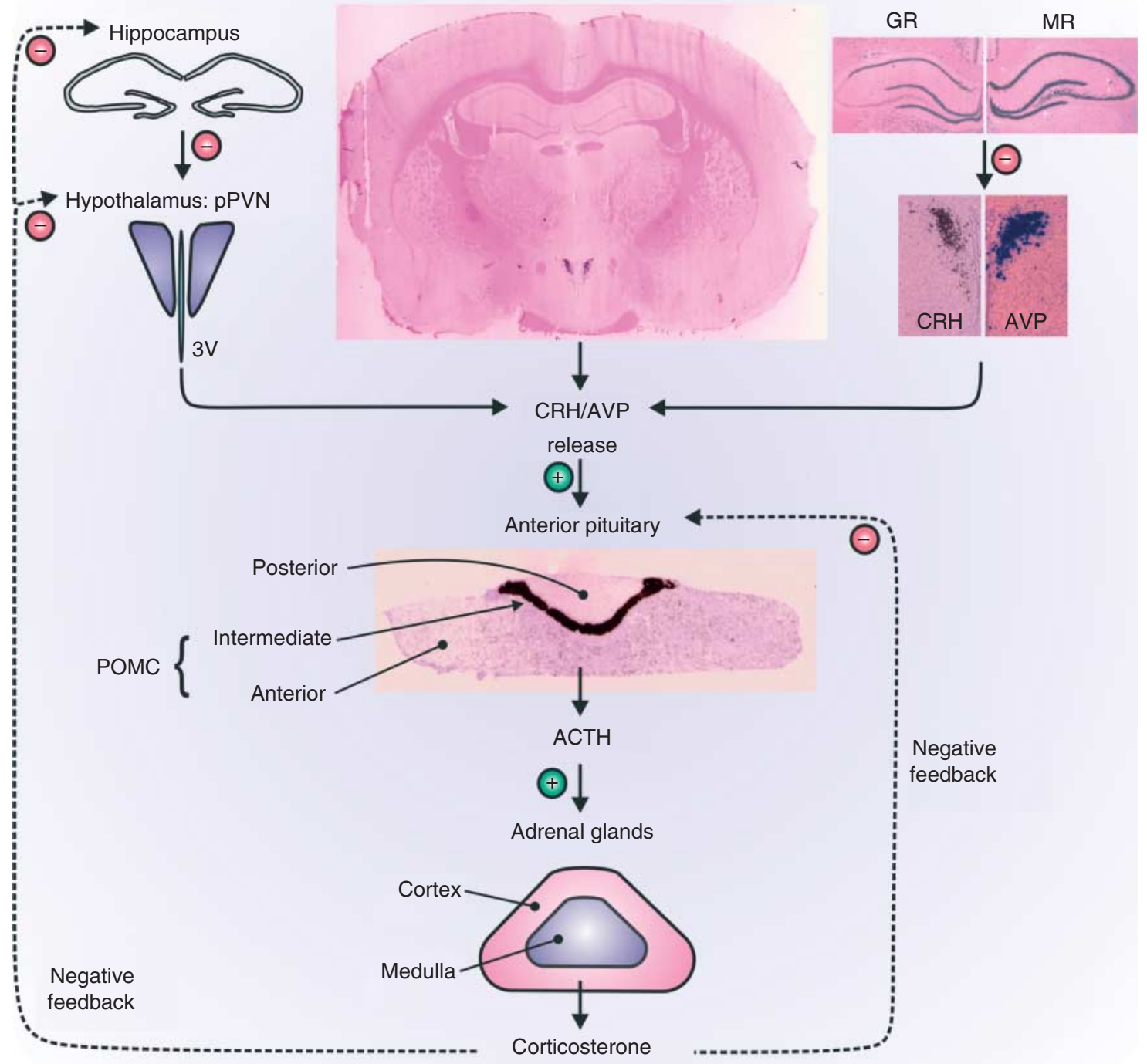

Figure 1 The HPA axis. Stressful stimuli activate neurosecretory corticotrophin-releasing hormone (CRH) and arginine vasopressin (AVP) neurones located in the parvocellular region of the paraventricular nucleus (pPVN) in the hypothalamus. Upon activation, these neurones release $\mathrm{CRH}$ and AVP from their nerve terminals at the median eminence into the hypophysial portal blood system. CRH and AVP stimulate (+) adrenocorticotrophic hormone $(\mathrm{ACTH})$ release from anterior pituitary corticotrophs and an increase in the expression of the ACTH precursor, pro-opiomelanocortin, mRNA in the anterior pituitary. ACTH in turn stimulates the secretion of glucocorticoids (corticosterone in rats and cortisol in pigs) from the adrenal cortex. Glucocorticoids inhibit their own release by providing negative feedback inhibition ( - ) via glucocorticoid receptors expressed in the hippocampus, PVN and anterior pituitary and via mineralocorticoid receptors expressed in the hippocampus. $3 \mathrm{~V}$, third ventricle.

out in rodents. Multiple paradigms are reported in the literature, such as exposure of pregnant rats, mice or guinea pigs to repeated restraint (Henry et al. 1994), immobilisation (Ward \& Weisz 1984), noise (Fride \& Weinstock 1984), strobe lighting (Kapoor \& Matthews 2005), social stress (Bosch et al. 2007, Brunton \& Russell 2010), electric shocks (Takahashi \& Kalin 1991), hypoxia (Fan et al. 2009) or chronic variable stress (exposure to a combination of different stressors on an unpredictable basis; Koenig et al. 2005, Lee et al. 2007, Mueller \& Bale 2008), either throughout or during a specific period of gestation.
It can be argued that many of these models are not accurate reflections of the type of stress women are likely to experience during pregnancy, which often have a social basis, for example, bullying, pressure at work/heavy workload, bereavement, intimate partner abuse or social instability/disadvantage (Bjorkqvist 2001, Valladares et al. 2009, Lee et al. 2011, Katz 2012, Laszlo et al. 2013, Mahenge et al. 2013); thus, animal models of prenatal stress that involve a social component may provide better insight for translational approaches.

The aim of this article is to review the effects of social stress exposure during pregnancy on the offspring. 
The article mainly focuses on rodent models of social stress, but it also considers models in other larger species. Sex differences in the sensitivity to programming are considered, and using evidence from other models of prenatal stress, what is known about the mechanisms involved is discussed. Finally, the possible mechanisms through which maternal stress exposure is transmitted to the foetus and the possibility of reversing the detrimental effects of foetal programming are explored.

\section{Animal models of social stress during pregnancy Rodent model of prenatal social stress}

Several animal models of social stress have been devised, including social isolation and overcrowding; however, the resident-intruder paradigm is probably the most commonly utilised one (Blanchard et al. 2001). In this model, an 'intruder' is transferred into the home cage of a 'resident' (usually a same-sex unfamiliar conspecific) for a specified period of time. This is generally carried out using male rodents and results in the resident being aggressive towards the intruder, which exhibits submissive behaviour. Females are typically less aggressive than males, with the exception of the first half of the lactation period when dams attack unfamiliar intruders that approach the nest in order to defend their pups (Brunton \& Russell 2010). Hence, pregnant rats can be reliably exposed to social stress by placing them into a cage with an unfamiliar lactating mother. In our laboratory, pregnant 'intruder' rats were exposed to a lactating 'resident' (lactation days 2-8) for $10 \mathrm{~min} /$ day on five consecutive days from days 16 to 20 of pregnancy (Brunton \& Russell 2010).

\section{Pig model of prenatal social stress}

Pigs have also been used to model the effects of exposure to social stress during pregnancy. These studies have relevance not only to humans, but also to the welfare of livestock. In European Union (EU) countries, legislation related to the housing conditions for pigs (Council Directive 2001/88/EC, which applies to all pig holdings in EU member states from 1st January 2013) has led to sows being group housed (rather than being individually housed in close-confinement stalls/farrowing crates) to ensure unrestricted movement and social interaction. However, as pigs form a social dominance hierarchy, the consequent mixing of unfamiliar pregnant pigs leads to aggressive behaviour, injury and HPA stress axis activation, providing a model to evaluate adverse offspring outcomes (Jarvis et al. 2005).

In the experimental model, a pair of young primiparous pregnant sows are housed in a new pen with two older unfamiliar multiparous (but not pregnant) sows for two 7-day periods in either the second or the third trimester, while control sows remain in their home pen (with age-matched familiar conspecifics) and are undisturbed during gestation. This social mixing results in the older sows being aggressive towards the younger sows to establish social dominance (Jarvis et al. 2005). The socially mixed pregnant young sows display submissive behaviours, decreased weight gain, increased body lesions as a result of aggressive social interactions and increased salivary cortisol levels (Jarvis et al. 2005), indicating the activation of the HPA axis (Fig. 1).

\section{Effects of social stress on pregnancy outcomes in rodents}

Social stress exposure during pregnancy can negatively affect pregnancy outcomes, though the effects depend upon the frequency and severity of the stress and when during pregnancy the stress occurs. In hamsters, social stress exposure (social defeat by a dominant conspecific) during early pregnancy results in significantly smaller litter sizes and reduced birth weight for both male and female pups (Pratt \& Lisk 1991). Moreover, there is a significant reduction in the number of males per litter, indicating selective resorption/spontaneous abortion of males in utero (Pratt \& Lisk 1991). Similar effects on litter size have also been reported in mice exposed to psychosocial stress (exposure to a rat or rat odour) in early pregnancy (de Catanzaro 1988).

These effects of stress on pregnancy loss are associated with a significant reduction in circulating progesterone levels and can be prevented by exogenous progesterone administration (Pratt \& Lisk 1991). Exposure to other types of stressors during early pregnancy has also been shown to reduce circulating progesterone levels in mice (Parker et al. 2011), and in women low progesterone levels in early pregnancy can predict miscarriage (Arck et al. 2008). In rodents, maintenance of progesterone secretion and hence the pregnancy relies on the action of luteinising hormone (LH) on the corpora lutea. How the effects of social stress on pregnancy loss are mediated is not fully understood; however, the activation of the maternal HPA axis is likely to be involved. Stress elicits a robust HPA axis response in rodents in early pregnancy (Neumann et al. 1998, Brunton et al. 2008), and reduced progesterone secretion through corticotrophin-releasing hormone $(\mathrm{CRH})$-mediated suppression of hypothalamic gonadotrophin-releasing hormone (GNRH) secretion and glucocorticoidmediated inhibition of GNRH secretion from the hypothalamus and $\mathrm{LH}$ release from the anterior pituitary is well established (Rivier et al. 1986, Kamel \& Kubajak 1987, Chrousos et al. 1998; Fig. 2).

Reduced litter size and litter weight have been reported in rats exposed to chronic social stress (2 h/day) throughout gestation (Gotz et al. 2008). Whereas brief social stress during late pregnancy (10 min/day on days 16-20) in rats does not affect litter size at birth, birth weight is significantly reduced in the 


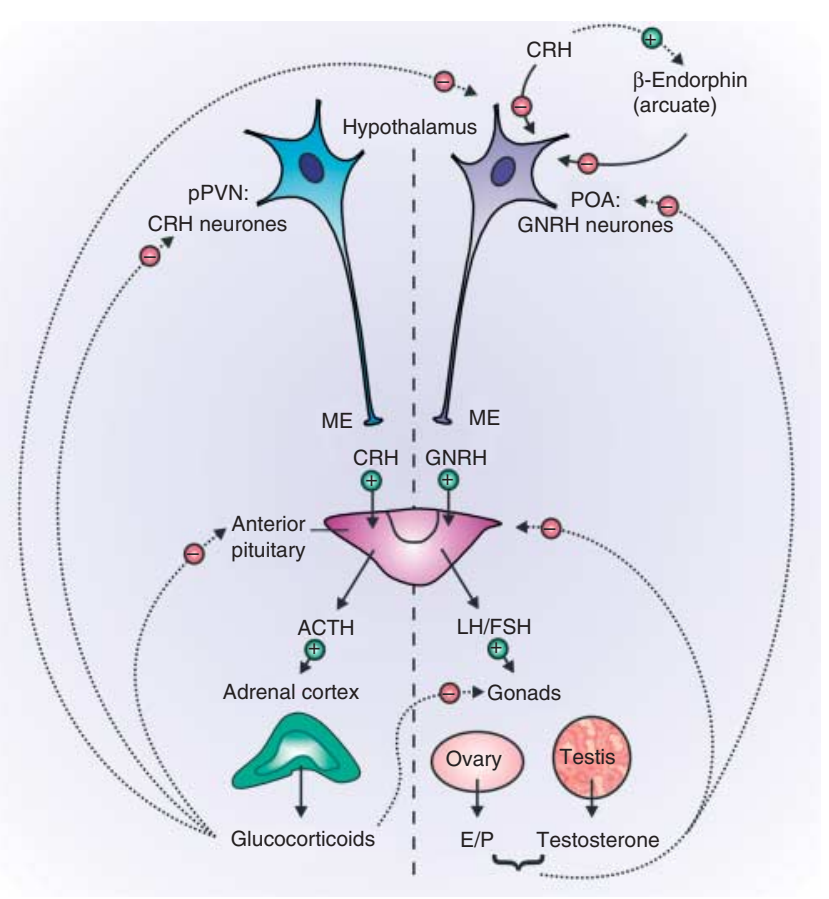

Figure 2 Interactions between the HPA and hypothalamic-pituitarygonadal (HPG) axes. HPG axis: GNRH neurones in the preoptic area (POA) in the hypothalamus synthesise and secrete GNRH from their terminals at the median eminence (ME). GNRH acts on gonadotrophs in the anterior pituitary gland to stimulate $(+)$ the synthesis and release of $\mathrm{LH}$ and follicle-stimulating hormone (FSH) into the blood. In the testis, LH stimulates testosterone production in Leydig cells, while FSH stimulates spermatogenesis. In the ovary, FSH controls follicular maturation and oestradiol $\left(\mathrm{E}_{2}\right)$ production, while $\mathrm{LH}$ regulates ovulation and progesterone secretion by the corpus luteum. Gonadal sex steroid hormones exert negative feedback (-) actions at the level of the hypothalamus and the anterior pituitary. HPA axis: stress exposure activates $\mathrm{CRH}$ neurones in the parvocellular division of the paraventricular nucleus ( $\mathrm{pPVN}$ ) in the hypothalamus, triggering $\mathrm{CRH}$ release at the ME. CRH stimulates ACTH release from the anterior pituitary, which in turn stimulates glucocorticoid secretion from the adrenal cortex. Glucocorticoids exert negative feedback control at the level of the anterior pituitary and PVN (see Fig. 1). HPA-HPG axis interactions: glucocorticoids influence the HPG axis at multiple levels. In the hypothalamus, glucocorticoids inhibit the synthesis and release of GNRH, and in the anterior pituitary, glucocorticoids inhibit LH secretion. Glucocorticoid receptors are expressed in the ovaries and testes and glucocorticoids act here to inhibit gonadal steroidogenesis. Increased CRH levels as a consequence of stress also inhibit the GNRH neurones either directly or indirectly via stimulation of $\beta$-endorphin in the arcuate nucleus.

prenatally stressed female offspring with a tendency for reduced birth weight in the male offspring (Brunton \& Russell 2010). The number of prenatally stressed pups surviving between birth and weaning is also reduced compared with that of controls, and this does not appear to be a result of increased infanticide in gestationally stressed dams (N J Grundwald, Y-T Lai \& P J Brunton 2012, unpublished observations). Similarly, overcrowding stress during the second half of pregnancy in mice results in pups of reduced birth weight with no effect on litter size (Zielinski et al. 1991). Maternal HPA axis responses to stress are significantly attenuated in late pregnancy in rats (Brunton et al. 2009) and mice (Douglas et al. 2003), including in response to social stress (Brunton \& Russell 2010), which may explain the contrasting effects of social stress exposure during early and late pregnancy on litter size. While stress during early pregnancy causes robust activation of the maternal HPA axis (Brunton et al. 2008), which can mediate the inhibition of progesterone secretion (as described above) and hence pregnancy loss, stress during late pregnancy is not expected to have such an effect on progesterone secretion due to suppressed maternal HPA axis responses (Neumann et al. 1998, Brunton et al. 2005, 2008), which may protect against pregnancy failure.

Stress-induced pregnancy loss in early gestation may be an adaptive mechanism that minimises investment in a pregnancy in suboptimal conditions and conserves maternal resources/energy for survival, while in late pregnancy, when the mother has already invested significant resources in the foetuses, the pregnancy is maintained despite stress exposure. There are, however, several other detrimental consequences of social stress exposure during pregnancy, especially for the offspring: it seems that where pregnancy loss does not occur in utero, foetal programming does. The subsequent sections focus on such adverse effects of prenatal social stress on the offspring in later life.

\section{Effects of prenatal social stress on stress responsivity in the offspring}

\section{Stress responsivity in prenatally stressed rodents}

Generally, prenatally stressed rodents display greater HPA axis responses to acute stress prior to puberty onset (Henry et al. 1994) and in adulthood (Weinstock et al. 1992, Henry et al. 1994, McCormick et al. 1995, Bosch et al. 2007, Brunton \& Russell 2010) and responses are prolonged compared with those of controls (Henry et al. 1994, Barbazanges et al. 1996, Brunton \& Russell 2010). This is also the case for offspring born to mothers exposed to social stress during pregnancy (Abe et al. 2007, Bosch et al. 2007, Brunton \& Russell 2010), where both the male (Abe et al. 2007, Brunton \& Russell 2010) and female (Bosch et al. 2007, Brunton \& Russell 2010) offspring display markedly greater adrenocorticotrophic hormone (ACTH) and corticosterone responses to physical (e.g. immune challenge) and psychological (e.g. restraint and elevated platform exposure) stressors in adulthood compared with control offspring.

\section{Stress responsivity and emotionality in prenatally stressed pigs}

Prenatal social stress does not appear to affect piglet birth weight (as has been reported in rodent models of prenatal 
social stress (Brunton \& Russell 2010)), viability or mortality; however, the female prenatally stressed piglets gain weight more slowly than controls and adapt less well to being separated from their mothers and housed in a novel environment at weaning (Jarvis et al. 2005), an event that is considered to be stressful (Mason et al. 2003). Moreover, increased serotonin turnover in the hippocampus has been reported in response to weaning in piglets born to socially stressed mothers, which may contribute to increased emotionality (Otten et al. 2010).

In response to an acute social stress at 10 weeks, prenatally stressed female pigs (males have not been tested) display increased and more prolonged salivary cortisol responses compared with controls (Jarvis et al. 2005), further indicating enhanced stress reactivity in prenatally stressed offspring.

\section{Central mechanisms of enhanced stress reactivity}

It is widely considered that the increased susceptibility to adulthood diseases and many of the negative phenotypes observed in prenatally stressed offspring (described above) are underpinned by the dysregulation of the HPA axis (Levitt et al. 2000). Therefore, it is appropriate to focus on what is known about the mechanisms involved in altered HPA axis activity in prenatally stressed offspring.

Enhanced ACTH and hence corticosterone responses to stress in the male offspring of rats exposed to social stress prenatally result from increased drive by the ACTH secretagogues, released by parvocellular neurones in the paraventricular nucleus (pPVN) in the hypothalamus, as indicated by greater levels of $C r h$ mRNA and arginine vasopressin (Avp) mRNA in the pPVN following stress (Brunton \& Russell 2010; Fig. 3). Notably, there is a sex difference in the expression profiles of these genes: in contrast to males, only Crh mRNA levels and not Avp mRNA levels are greater in prenatally stressed females than in controls after an immune challenge (systemic interleukin 1 $\beta$; Brunton \& Russell 2010). Nonetheless, greater HPA axis responses to stress in both male and female offspring are evidently the result of increased drive by the hypothalamic CRH neurons in the pPVN (Brunton \& Russell 2010).

Consistent with these findings in rodents is the finding of elevated basal Crh mRNA expression in the PVN and in the amygdala of female prenatally stressed pigs compared with controls (Jarvis et al. 2005). Given the central role of $\mathrm{CRH}$ in the regulation of the HPA axis and in anxiogenesis (see below; Schulkin et al. 1998), this may explain the increased HPA axis reactivity and heightened emotional responses to stressful experiences in the prenatally stressed pigs (Jarvis et al. 2005).

The enhanced and prolonged HPA axis responses to stress in the offspring of mothers exposed to social stress during pregnancy are not fully understood; however, impaired negative feedback control has been proposed. The HPA axis is under negative feedback control by glucocorticoids, which function to terminate stress responses (Fig. 1). In rats, prenatal stress exposure results in the reduced expression of glucocorticoid receptors (GRs; Weinstock et al. 1992), mineralocorticoid receptors (MRs; Barbazanges et al. 1996) or both GRs and MRs in the hippocampus of the offspring (Henry et al. 1994), depending on the nature and timing of the prenatal stress exposure and the sex of the offspring. In the case of prenatal social stress, Nr3c2 (Mr) mRNA expression is significantly reduced in the hippocampus of the male and female offspring (Brunton \& Russell 2010), whereas Nr3c1 (Gr) mRNA expression is largely unaffected in either the hippocampus or the PVN (Brunton \& Russell 2010) (Fig. 3). Thus, reduced hippocampal MR expression may contribute to impaired feedback control of the HPA axis, but this is yet to be functionally tested.

The mechanism by which hippocampal corticosteroid receptor expression is reduced in prenatally stressed offspring is unclear. Nevertheless, GRs and MRs can be detected in the foetal hippocampus from gestational days 13 and 16 respectively (Diaz et al. 1998); thus, it is conceivable that the elevated levels of maternal glucocorticoids could interact with the $\mathrm{Nr} 3 \mathrm{c} 1$ and/or $\mathrm{Nr} 3 \mathrm{c} 2$ promoters to alter gene expression. Epigenetic mechanisms could provide a means through which gene expression is permanently altered in prenatally stressed animals. For example, in mice, the adult male offspring of mothers exposed to chronic variable stress during early pregnancy exhibit hyperactive HPA axis responses to stress, concomitant with increased Crh mRNA expression in the PVN and reduced hippocampal Nr3c1 mRNA expression (Mueller \& Bale 2008). This is associated with hypomethylation of the $\mathrm{Crh}$ promoter and hypermethylation of the $\mathrm{Nr} 3 \mathrm{C} 1$ gene (Mueller \& Bale 2008), consistent with the up- and down-regulation of $\mathrm{Crh}$ and $\mathrm{Nr} 3 \mathrm{C} 1$ gene expression respectively.

\section{Effects on anxiety-like behaviour in prenatally stressed offspring}

Adult male offspring of rats exposed to social stress during pregnancy display increased anxiety-related behaviour on the elevated plus maze (Brunton \& Russell 2010) and in the open field (Abe et al. 2007) and increased depression-like behaviour in a forced swim test (Abe et al. 2007), consistent with the findings of studies using other prenatal stress paradigms (Poltyrev et al. 1996, Vallee et al. 1997). By contrast, prenatal social stress in late pregnancy does not appear to affect anxiety-type behaviour in female offspring (Brunton \& Russell 2010), except when given in combination with another psychological stressor (restraint) in early-mid pregnancy (Bosch et al. 2007). Other studies using different prenatal stress models in rats have also reported sex differences (Zagron \& Weinstock 2006, Mueller \& Bale 2008), including reduced anxiety in 


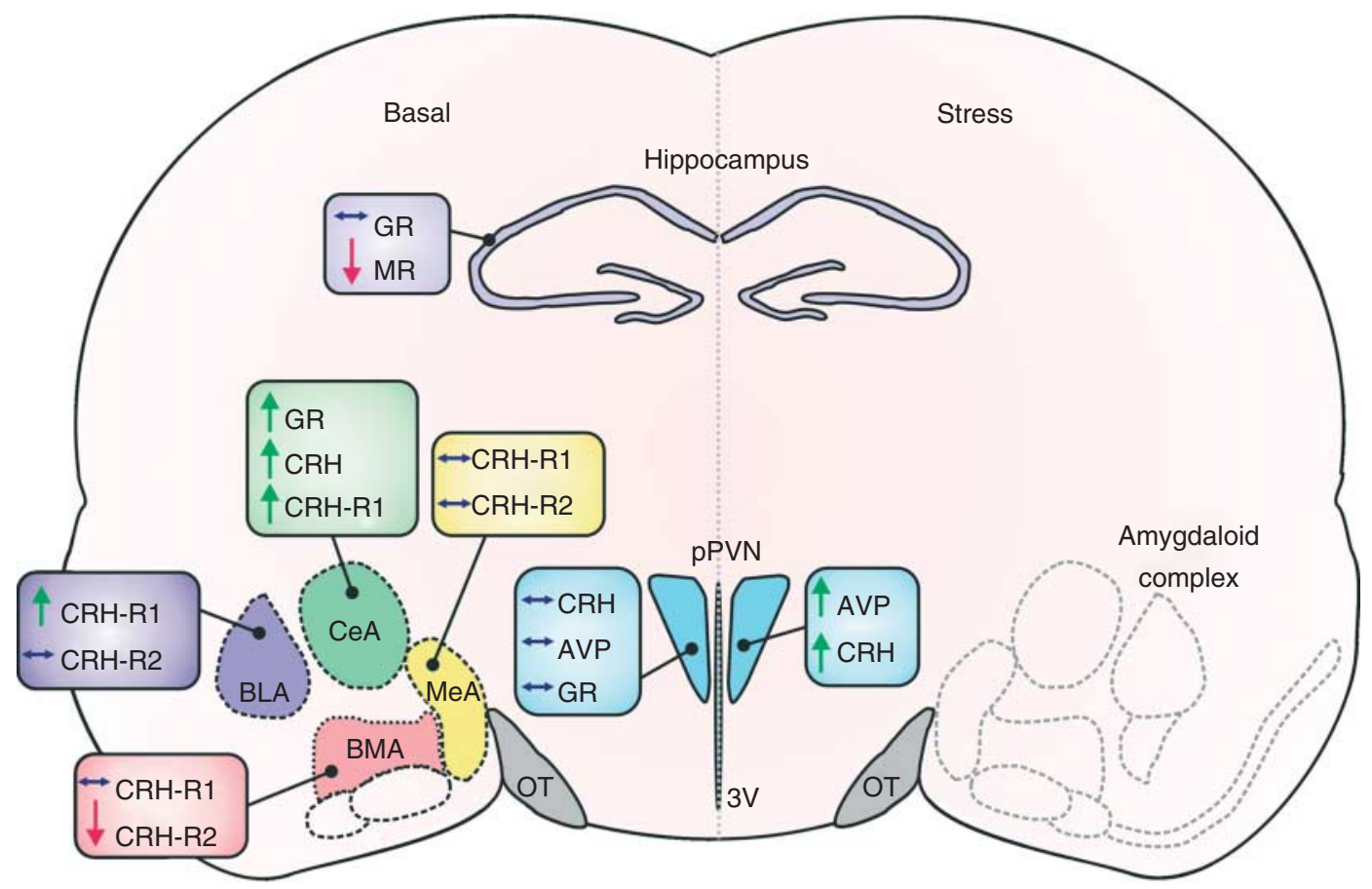

Figure 3 Changes in the brain of the offspring following prenatal social stress. Summary diagram illustrating the major differences in mRNA expression found in the brain of adult male prenatally stressed rats (mother was exposed to social stress, 10 min/day on days 16-20 of pregnancy) compared with control male offspring, under basal conditions (left) and following stress (right; 4-h post-interleukin $1 \beta$ administration). $\uparrow$, Greater expression; $\downarrow$, lower expression and $\leftrightarrow$, no difference in mRNA expression compared with that in control rats. $3 \mathrm{~V}$, third ventricle; BLA, basolateral amygdala; BMA, basomedial amygdala; CeA, central amygdala; CRH-R1, CRH receptor type 1; MeA, medial amygdala; OT, optic tract. Data are based on the studies of Brunton \& Russell (2010) and Brunton et al. (2011).

prenatally stressed females compared with males (Zuena et al. 2008).

$\mathrm{CRH}$ neurones in the central nucleus of the amygdala (CeA) are considered to be particularly important in the mediation of anxious behavioural responses (Schulkin et al. 1998); hence, central administration of CRH induces anxiety-like behaviour (Dunn \& Berridge 1990), while a $\mathrm{CRH}$ antagonist given centrally can block fear responses in prenatally stressed rats (Ward et al. 2000). Therefore, increased anxiety-like behaviour in prenatally stressed rats may be mediated via enhanced central CRH release or action (Dunn \& Berridge 1990).

Both male and female offspring of dams exposed to social stress during pregnancy have increased levels of Crh mRNA in the CeA (Brunton \& Russell 2010; Fig. 3), consistent with the finding of increased $\mathrm{CRH}$ content and mRNA expression in the amygdala from other prenatal stress models in rats (Cratty et al. 1995) and mice (Mueller \& Bale 2008) and in the offspring of pigs whose mothers were exposed to social stress during gestation (Jarvis et al. 2005). These changes probably involve facilitation by glucocorticoids, as glucocorticoids upregulate $\mathrm{Crh}$ gene expression in the amygdala (Makino et al. 1994) and central GRs facilitate anxiety-type behaviours; moreover, Nr3c1 mRNA levels are up-regulated in the amygdala in prenatally stressed rats (McCormick et al. 1995, Brunton \& Russell 2010). However, this does not explain the increased anxietyrelated behaviour in the male offspring of mothers exposed to social stress during pregnancy as both sexes exhibit elevated Crh mRNA expression in the CeA, but only the males exhibit an anxious phenotype (Brunton \& Russell 2010). Nonetheless, altered CRH receptor expression may play a role in this sex difference.

There are two $\mathrm{CRH}$ receptors through which $\mathrm{CRH}$ exerts its actions. The activation of the type 1 receptor (CRH-R1) mediates HPA axis responses and anxiety-like behaviours, whereas that of the type 2 receptor (CRH-R2) mediates the anxiolytic actions of urocortins 2 and 3 (Bale \& Vale 2004). The expression of mRNA for the two $\mathrm{CRH}$ receptors is altered by prenatal social stress, and importantly there are distinct sex differences (Brunton et al. 2011). In prenatally stressed males, but not in females, Crhr1 mRNA levels are greater in the CeA and basolateral amygdala than in those in unstressed controls (Brunton et al. 2011; Fig. 3). Moreover, Crhr2 mRNA expression is reduced in the basomedial amygdala (BMA) in prenatally stressed males (Fig. 3) and increased in the BMA in prenatally stressed females (Brunton et al. 2011). This differential CRH receptor mRNA expression 
in the amygdaloid complex in prenatally stressed males and females may underlie the difference in anxiety-like behaviour following social stress exposure in late gestation. Indeed, in other prenatal stress models where both sexes exhibit heightened anxiety, reduced Crhr2 expression is observed in the amygdala in both sexes (Zohar \& Weinstock 2011). It is not known whether these changes in $\mathrm{CRH}$ receptor expression in the amygdala result from changes in DNA methylation in the promoter regions of the $\mathrm{CRH}$ receptor genes, as has been shown for Crhr1 mRNA expression in the PVN in anxious male offspring of mothers exposed to hypoxia throughout gestation (Wang et al. 2013).

\section{Effects on nociception in prenatally stressed offspring}

There is also evidence from pigs that maternal exposure to social stress during gestation induces alterations in sensitivity and responsiveness to pain in the offspring. Tail-docking is a routine husbandry practice (to prevent injury by tail-biting), which is performed in the early postnatal period ( $\sim 3$ days old) without anaesthesia/ analgesia (Hunter et al. 2001). Piglets born to mothers exposed to social stress during pregnancy exhibit significantly greater pain scores (independent of sex) in response to tail-docking compared with tail-docked piglets born to control sows (Rutherford et al. 2009), indicating that prenatally stressed piglets are more sensitive to pain. Remarkably, the pain score in the piglets positively correlates with maternal cortisol levels during the social stress (Rutherford et al. 2009), indicating that nociception in the offspring is influenced by the gravity of the mother's stressful experience. Similar findings have been observed in humans: the greater the levels of maternal cortisol and maternal psychosocial stress experienced in a woman during pregnancy, the greater her newborn baby's behavioural and cortisol response to a painful event after birth (heel prick blood test; Davis et al. 2011).

In contrast to findings in neonatal prenatally stressed piglets, studies assessing nociception after weaning (age 5-8 weeks) have found that prenatal stress is associated with increased nociceptive thresholds (e.g. hypoalgesia) in response to noxious mechanical or cold stimulation under basal conditions and in response to acute inflammation in both sexes, indicative of reduced sensitivity to pain (Sandercock et al. 2011). Hence, while prenatally stressed pigs are more behaviourally reactive to a painful challenge (tail-docking) in the neonatal period, it appears that basal nociception and inflammation-evoked nociception are reduced in later life in prenatally stressed pigs. This indicates a possible divergence in responses to the sensory and affective components of pain in prenatally stressed pigs. Whether this is a result of changes in stress-induced analgesia requires further investigation. However, it is interesting to note that stress-induced analgesia interacts with behavioural performance in an inverted U-shape, with mild stress facilitating and more severe stress disrupting appropriate behavioural responses (Amit \& Galina 1988).

\section{Effects on metabolism}

It has recently been shown that prenatal social stress also has sex-dependent effects on glucose, insulin and lipid homoeostasis in the adult offspring (Brunton et al. 2013). Prenatal stress is associated with stressinduced hyperglycaemia in males, but not in females, and with hyperinsulinaemia in response to glucose loading in females, but not in males (Brunton et al. 2013). Moreover, the expression of genes important in glucocorticoid and lipid metabolism is altered by prenatal social stress predominantly in the liver and skeletal muscle in the male rats, whereas in female rats the majority of changes are observed in subcutaneous fat (Brunton et al. 2013). Thus, prenatal social stress exposure is associated with sex-specific alterations in the periphery that indicate increased insulin resistance and an increased risk of metabolic dysfunction in adulthood.

\section{Effects on the reproductive axis and reproductive behaviours in the offspring}

Limited evidence from studies in pigs indicates that prenatal exposure of pregnant sows to social stress may also affect the development of the reproductive axis in the male and female offspring (Ashworth et al. 2011). In pre-pubertal females, prenatal stress significantly reduces the number of primordial follicles in the ovaries (Ashworth et al. 2011). The long-term effects of this are unclear; however, studies in women indicate that the ovarian follicle pool may predict reproductive capacity in later life. Hence, the number of primordial follicles prior to puberty onset governs the rate at which primordial follicles are recruited for folliculogenesis: the number of follicles recruited is inversely proportional to the number of primordial follicles (Gougeon et al. 1994). Thus, assuming that primordial follicles are depleted more rapidly, one may predict premature reproductive senescence in prenatally stressed females, though this requires further study.

In pre-pubertal male pigs, prenatal stress is associated with a significant reduction in the circulating levels of the sex steroids, testosterone and oestradiol. Whether this altered steroidogenesis in prenatally stressed males will be a factor in future reproductive capacity is not known, but it warrants further investigation. Reduced testosterone levels are of particular interest, since in rats prenatal stress exposure blocks the normal prenatal surge in circulating testosterone levels that occurs in male foetuses in late gestation (Ward \& Weisz 1980), and 
this block results in the demasculinisation and feminisation of sexual behaviours in adulthood (Ward 1972). Moreover, given that testosterone is known to exert inhibitory actions over HPA axis activity and anxiety behaviour (Handa et al. 1994, Edinger \& Frye 2005), reduced testosterone levels in prenatally stressed male pigs may predict a propensity for increased stress reactivity (as has been described above for female prenatally stressed pigs). Indeed, reduced testosterone levels have been shown to underpin increased stress reactivity and increased behavioural indicators of anxiety in a guinea pig model of prenatal stress (Kapoor \& Matthews 2011).

To date, few studies have directly assessed the effects of social stress exposure during pregnancy on the future reproductive capacity of the offspring in rodents. In rats exposed to chronic social stress (2-h daily exposure to a dominant female) throughout pregnancy, no effects on reproductive parameters were found in the F1 female offspring, such as age at which their first litter was produced and the total number of litters and number of pups produced; however, the time of day at which prenatally stressed females gave birth was shifted from the light phase to the dark phase (Gotz et al. 2008). Nevertheless, other prenatal stress models (exposure to repeated restraint under bright lighting for 7 days in late pregnancy) have reported altered reproductive behaviours in prenatally stressed F1 females at the time of mating, including increased aggression towards the male, increased avoidance of the male, reduced solicitation behaviour, and reduced incidence and intensity of lordosis (Frye \& Orecki 2002), and impaired adult male sexual performance (Holson et al. 1995). Moreover, the male rats of mothers exposed to immobilisation ( $2 \mathrm{~h} /$ day for 5 consecutive days) in late gestation show reduced sexual motivation towards and reduced copulatory activity with receptive females in adulthood (Wang et al. 2006). It is not yet known whether similar effects can be observed in rodents following prenatal social stress exposure; however, the social stress of overcrowding during pregnancy is associated with masculinisation of female pups (Zielinski et al. 1991).

\section{Effects on maternal behaviour in the female offspring Maternal behaviour in rodents}

While we did not find any differences in the subsequent maternal behaviour of rats exposed to social defeat during late pregnancy (N J Grundwald \& P J Brunton 2012, unpublished observations), one study has reported reduced mother-pup interactions following social crowding during the last week of pregnancy (Moore \& Power 1986). This was reflected by reduced anogenital licking of the pups by the dam and intriguingly occurred regardless of the pups being reared by their biological mother (hence gestationally stressed) or by an unstressed foster mother, indicating that the prenatally stressed pups elicit less maternal licking (Moore \& Power 1986). These data are of particular interest with regard to the future sexual behaviour of the offspring, considering that male pups generally receive more anogenital licking than females, an effect that is mediated by testosteronedependent cues (Moore 1982), and because both prenatal stress and decreased maternal licking of pups are associated with deficits in male sexual behaviour in later life (Ward 1972, Moore 1984).

Prenatal social stress has also been shown to negatively affect maternal care in the female F1 offspring when they themselves become mothers (Bosch et al. 2007). Prenatally stressed dams exhibit lower levels of nursing behaviour and spend less time in direct contact with their pups compared with controls (Bosch et al. 2007). This is associated with elevated levels of $\mathrm{Crh}$ mRNA in the pPVN under basal conditions. It is not known whether prenatal social stress affects $\mathrm{CRH}$ expression in other regions of the brain; however, as the activation of the central CRH system is known to impair maternal behaviour (Pedersen et al. 1991, Gammie et al. 2004, Klampfl et al. 2013), this may contribute to reduced mother-pup interactions and reduced nursing.

\section{Maternal behaviour in pigs}

While socially mixed mothers do not show any differences in maternal behaviour post partum compared with control sows, interestingly and as in rats, when their female offspring become mothers, deficits in maternal behaviour can be observed, including a tendency to be more aggressive towards their piglets (Jarvis et al. 2005). This altered maternal behaviour is associated with an anxiety-prone phenotype and altered $\mathrm{CRH}$ receptor expression in the amygdala in the prenatally stressed females (K Rutherford 2012, personal communication).

Thus, prenatal stress exposure evidently exerts a longterm effect on future behaviour. Given that postnatal maternal care has also been shown to programme stress responsivity and emotionality in the offspring (Champagne \& Meaney 2001, Weaver et al. 2004) and furthermore to programme subsequent maternal behaviour in female offspring (Champagne \& Meaney 2001, Palombo et al. 2010), a further consequence of prenatal social stress is the potential transmission of the programmed phenotype to future generations.

\section{Transmission of prenatal stress effects from the mother to the foetus}

The mechanisms responsible for the transmission of the effects of maternal stress to the foetus(es) are unclear; however, maternal glucocorticoids and/or 
catecholamines, foetal HPA axis responses and deficits in maternal behaviour may all play a role and are discussed below.

\section{Role for glucocorticoids?}

The exposure of the foetus(es) to excessive levels of maternal glucocorticoids as a result of stress has been proposed (Barbazanges et al. 1996, Welberg \& Seckl 2001) as one mechanism whereby the effects of maternal stress may be transmitted to the offspring. Pregnant rats or guinea pigs treated with a synthetic glucocorticoid (dexamethasone) produce offspring with phenotypes similar to those exposed to prenatal stress (Welberg et al. 2001, Kapoor \& Matthews 2005). Furthermore, maternal adrenalectomy (to prevent stress-induced increases in the levels of maternal glucocorticoids) abrogates some of the effects of prenatal stress in the offspring (Barbazanges et al. 1996). Nevertheless, a role for maternal glucocorticoids is debatable for two reasons. First, the placenta expresses $11 \beta$-hydroxysteroid dehydrogenase type 2 (11 $\beta$-HSD2; Benediktsson et al. 1997), which acts as a barrier to limit the exposure of the foetus to active maternal glucocorticoids by metabolising corticosterone/cortisol (depending on the species) into inactive 11-dehydrocorticosterone/ cortisone. Dexamethasone is a synthetic glucocorticoid and is not a substrate for $11 \beta$-HSD2; therefore, it can freely cross the placenta. Second, and as has been mentioned above, maternal HPA axis responses to stress are markedly attenuated in late pregnancy (Brunton et al. 2008).

Although repeated social stress in late pregnancy evokes maternal corticosterone secretion, the amplitude and duration of the response are drastically reduced in comparison with those in virgin rats (Brunton \& Russell 2010); moreover, the maximal levels of corticosterone achieved do not exceed those levels observed at the diurnal peak in gestation (Atkinson \& Waddell 1995). Despite this, the offspring of these socially stressed dams exhibit programmed phenotypes (e.g. reduced birth weight, increased HPA axis responses to stress and increased anxiety-like behaviour; Brunton \& Russell 2010), as has been described above, casting doubt on whether maternal glucocorticoids mediate the effects of maternal stress on the offspring. Nevertheless, the timing of elevated circulating corticosterone levels may be critical: an unanticipated peak in corticosterone secretion during the circadian nadir may in some way contribute to programming the foetuses in utero. Furthermore, exposure to repeated stress in late pregnancy significantly reduces the capacity to up-regulate the activity of placental $11 \beta$-HSD2 (Welberg et al. 2005), which means potentially increased exposure of the foetuses to maternal glucocorticoids. Lastly, in rats, the foetal adrenal glands are sufficiently developed to begin secreting glucocorticoids from embryonic day 16, and the foetal HPA axis is activated in response to maternal stress in late pregnancy (Ohkawa et al. 1991, Fujioka et al. 2003), giving rise to the possibility that glucocorticoids of foetal origin may contribute to programming of the foetal brain.

\section{Role for catecholamines?}

The removal of the maternal adrenal glands (as has been described above) not only removes the source of glucocorticoids but also removes other adrenal factors (e.g. catecholamines, sex steroids and their precursors, mineralocorticoids and opioids), some of which may also play a role in foetal programming. In late pregnancy, stress-induced adrenaline release from the adrenal medulla is reduced compared with that in non-pregnant rats (Vaha-Eskeli et al. 1992, Russell et al. 2008); however, noradrenaline responses are maintained, reflecting sympathetic nervous system activation (Vaha-Eskeli et al. 1992, Russell et al. 2008). Placental monoamine oxidase and catechol-O-methyltransferase metabolise maternal noradrenaline (Chen et al. 1974, 1976), but up to $12 \%$ can be transferred to the foetal compartment (Sodha et al. 1984), which may have adverse effects on the foetus(es). Elevated levels of circulating maternal catecholamines cause vasoconstriction of placental blood vessels, reducing placental blood supply and hence impairing the delivery of oxygen and nutrients to the foetuses. Given that hypoxia and nutrient restriction activate the foetal HPA axis (Edwards \& McMillen 2002, Roelfsema et al. 2005) and elicit foetal sympathetic-adrenomedullary stress responses $(\mathrm{Gu} \&$ Jones 1986), these responses may contribute to the foetal programming of HPA axis responsivity and anxiety-like behaviour in the adult offspring (Almeida et al. 1996, Lingas \& Matthews 2001, Nunez et al. 2008, Fan et al. 2009, Wang et al. 2013). The adrenal medulla also secretes $\beta$-endorphin following stress exposure, which may cross the placenta to influence the development of the foetal brain (Sandman et al. 1997).

\section{Altered maternal behaviour?}

Given that some of the models of prenatal stress alter post partum maternal behaviour (Moore \& Power 1986, Smith et al. 2004), it is important to take this into consideration in attempting to explain how the effects of stress during pregnancy are transmitted to the offspring. The early postnatal environment plays an important role in influencing HPA axis activity and anxiety-like behaviour in later life (Liu et al. 1997, Champagne \& Meaney 2001). A high level of maternal care is associated with reduced HPA axis responses to stress and reduced anxiety-like behaviour in the adult offspring, whereas low levels of maternal care or long periods of maternal separation produce the opposite 
effects in the offspring (Liu et al. 1997, Champagne \& Meaney 2001). The mechanisms responsible involve epigenetic programming of the glucocorticoid feedback regulation of the HPA axis (Weaver et al. 2004). Thus, prenatal stress paradigms that result in deficits in maternal behaviour post partum may also contribute to the programming of the offspring.

\section{Reversal of foetal programming effects induced by stress exposure in pregnancy}

\section{Role for neurosteroids?}

Studies attempting to reverse the programming effects of prenatal stress exposure are ongoing. The neurosteroid metabolites of the sex steroids, progesterone and testosterone, are a particular focus for several reasons. First, as has been mentioned above, several prenatal stress paradigms have demonstrated consequent masculinisation of the female offspring and/or demasculinisation/feminisation of the male offspring (Ward 1972, Zielinski et al. 1991, Holson et al. 1995, Wang et al. 2006), indicating that prenatal stress interferes with the development of the hypothalamicpituitary-gonadal axis (Fig. 2). Second, the normal postpubertal sex differences in HPA axis function, whereby responses to stress in females exceed those observed in males, can be explained by differences in the types of sex steroids produced: specifically, testosterone reduces while oestrogen enhances HPA axis responses to stress (Handa et al. 1994). Finally, the $5 \alpha$-reduced metabolites of progesterone and testosterone, allopregnanolone and androstandiol, respectively have been shown to have anxiolytic actions and to suppress HPA axis responses to stress (Patchev et al. 1994, 1996, Frye \& Rhodes 2006, Lund et al. 2006, Brunton et al. 2009), implicating them as putative candidates for normalising the stress-hyperactive and -anxious phenotype in prenatally stressed animals.

Prenatal stress exposure has been linked to reduced levels of allopregnanolone, due to reduced conversion of progesterone to its $5 \alpha$-reduced metabolites ( $5 \alpha$-dihydroprogesterone and allopregnanolone), in the brains of juvenile rats and similarly to reduced levels of the $5 \alpha$-reduced metabolite of testosterone dihydrotestosterone in the brain of adult male offspring (Paris \& Frye 2011, Paris et al. 2011, Walf \& Frye 2012). These data indicate reduced neurosteroidogenesis in prenatally stressed offspring, probably as a result of reduced $5 \alpha$-reductase activity. Indeed, there is evidence for reduced central (P J Brunton \& J A Russell 2012, unpublished observations) and hepatic (Brunton et al. 2013) expression of $5 \alpha$-reductase mRNA in offspring exposed to prenatal social stress, which may contribute to reduced neurosteroid levels in the brain.

Short-term allopregnanolone treatment has been shown to normalise HPA axis responses to an acute stress challenge in adult female but not in male prenatally stressed rats. However, in prenatally stressed males, the $5 \alpha$-reduced metabolite of testosterone, androstandiol, is effective ( $\mathrm{P}$ J Brunton, $\mathrm{M} \vee \mathrm{V}$ Donadio \& J A Russell 2012, unpublished observations). Similarly, postnatal testosterone administration ameliorates behavioural deficits and elevates HPA axis function in prenatally stressed guinea pigs (Kapoor \& Matthews 2011). Whether this is a direct effect of testosterone actions or is mediated via testosterone metabolites (e.g. dihydrotestosterone and/or androstandiol) has not been tested. Nevertheless, $5 \alpha$-reduced steroids can evidently overwrite foetal programming by prenatal social stress, at least in terms of exaggerated HPA axis responses. In support of this is the finding that if allopregnanolone is administered to pregnant dams at the same time as they are exposed to gestational stress, enhanced anxiety behaviour in the juvenile and adult offspring is prevented (Zimmerberg \& Blaskey 1998). Whether postnatal allopregnanolone or androstandiol treatment exerts similar effects on anxiety-like behaviour or indeed reverses the impact of prenatal social stress on the other negative phenotypes observed in the offspring is as yet unknown.

\section{Postnatal environmental manipulations}

Brief maternal separation with neonatal handling produces persistent changes in HPA axis responsivity (Levine 1967). As adults, neonatally handled rats exhibit markedly attenuated HPA axis responses to stress concomitant with enhanced glucocorticoid negative feedback control of the HPA axis (Meaney et al. 1989). The effects of neonatal handling appear to be mediated by increased maternal care when the pups are returned after the brief separation (Liu et al. 1997). The manipulation of maternal care by brief neonatal handling has been shown to reverse the behavioural abnormalities (e.g. increased anxiety) associated with prenatal stress and to normalise HPA axis responses to stress (Wakshlak \& Weinstock 1990, Smythe et al. 1996, Vallee et al. 1997), although it is not known whether similar postnatal manipulations reverse foetal programming effects induced by prenatal social stress. The central mechanisms that underlie handling-induced changes in behavioural and neuroendocrine responses to stress are not fully understood; however, changes in GABAergic inhibition in the brain may be involved ( $\mathrm{Hsu}$ et al. 2003), which is noteworthy given the potent effects that neurosteroids exert via $\mathrm{GABA}_{\mathrm{A}}$ receptors (Belelli \& Lambert 2005).

\section{Summary and conclusions}

In this article, the evidence that social stress exposure during pregnancy has detrimental effects on the 
pregnancy and the offspring has been reviewed. Pregnancy outcomes depend upon when during gestation the stress is experienced, with stress in early gestation typically resulting in pregnancy loss, whereas later in gestation the pregnancy is maintained, although birth weights of the newborn(s) are significantly reduced and the prenatal stress has long-lasting programming effects on various systems in the offspring. In later life, prenatal social stress is generally associated with offspring that are hyper-responsive to stress and more anxious, as a result of changes in their brain. There are also indicators that the capacity to reproduce and reproductive/social behaviours may also be negatively affected. The finding that prenatal stress can programme future maternal behaviour highlights the potential for negative phenotypes to be transmitted to future generations.

Together, these findings have implications both for animal welfare in relation to livestock husbandry practices and for the management of pregnancy in women. Many epidemiological studies support the hypothesis that the experience of either physical or psychological stress in women during pregnancy can adversely programme their offspring. For example, there is an increase in the propensity for mild cognitive impairments and behavioural problems in children following prenatal stress (Laplante et al. 2008, Buss et al. 2012, Sandman et al. 2012) and increased susceptibility to develop cardiovascular and metabolic disease and neuropsychiatric disorders in later life (Entringer et al. 2008, Bale et al. 2010, Reynolds 2013).

Understanding how the effects of maternal stress during pregnancy are transmitted to the foetus(es) and the mechanisms involved in foetal programming as a result could aid the development of postnatal therapeutic interventions to reverse the detrimental effects observed in the offspring. In particular, understanding how resetting the activity of the HPA axis in offspring occurs following prenatal stress has important implications for humans since HPA axis hyperactivity is considered to underpin several adulthood pathologies (Phillips et al. 1998, Levitt et al. 2000). The prospects that adverse programming effects may be reversed by postnatal environmental manipulations or with neurosteroid administration are exciting areas that warrant further research.

\section{Declaration of interest}

The author declares that there is no conflict of interest that could be perceived as prejudicing the impartiality of the review reported.

\section{Funding}

The research performed in the laboratory of $\mathrm{P} J$ Brunton is funded by the Biotechnology and Biological Sciences Research Council (BBSRC) and by the British Society for
Neuroendocrinology. The Roslin Institute receives Institute Strategic Grant funding from the BBSRC.

\section{Acknowledgements}

The author expresses her gratitude to Prof. John A Russell (Centre for Integrative Physiology, University of Edinburgh) for critically reviewing the manuscript and to Mrs Helen Cameron (The Roslin Institute, University of Edinburgh) for providing the photographs used in the figures.

\section{References}

Abe H, Hidaka N, Kawagoe C, Odagiri K, Watanabe Y, Ikeda T, Ishizuka Y, Hashiguchi H, Takeda R, Nishimori T et al. 2007 Prenatal psychological stress causes higher emotionality, depression-like behavior, and elevated activity in the hypothalamo-pituitary-adrenal axis. Neuroscience Research 59 145-151. (doi:10.1016/j.neures.2007.06.1465)

Almeida SS, Tonkiss J \& Galler JR 1996 Prenatal protein malnutrition affects exploratory behavior of female rats in the elevated plus-maze test. Physiology \& Behavior 60 675-680. (doi:10.1016/S0031-9384(96) 80047-3)

Amit Z \& Galina ZH 1988 Stress induced analgesia plays an adaptive role in the organization of behavioral responding. Brain Research Bulletin 21 955-958. (doi:10.1016/0361-9230(88)90033-0)

Arck PC, Rucke M, Rose M, Szekeres-Bartho J, Douglas AJ, Pritsch M, Blois SM, Pincus MK, Barenstrauch N, Dudenhausen JW et al. 2008 Early risk factors for miscarriage: a prospective cohort study in pregnant women. Reproductive Biomedicine Online 17 101-113. (doi:10.1016/ S1472-6483(10)60300-8)

Ashworth CJ, Hogg CO, Hoeks CW, Donald RD, Duncan WC, Lawrence AB \& Rutherford KM 2011 Pre-natal social stress and post-natal pain affect the developing pig reproductive axis. Reproduction 142 907-914. (doi:10.1530/REP-11-0280)

Atkinson HC \& Waddell BJ 1995 The hypothalamic-pituitary-adrenal axis in rat pregnancy and lactation: circadian variation and interrelationship of plasma adrenocorticotropin and corticosterone. Endocrinology 136 512-520. (doi:10.1210/en.136.2.512)

Bale TL \& Vale WW 2004 CRF and CRF receptors: role in stress responsivity and other behaviors. Annual Review of Pharmacology and Toxicology 44 525-557. (doi:10.1146/annurev.pharmtox.44.101802. 121410)

Bale TL, Baram TZ, Brown AS, Goldstein JM, Insel TR, McCarthy MM, Nemeroff CB, Reyes TM, Simerly RB, Susser ES et al. 2010 Early life programming and neurodevelopmental disorders. Biological Psychiatry 68 314-319. (doi:10.1016/j.biopsych.2010.05.028)

Barbazanges A, Piazza PV, Le Moal M \& Maccari S 1996 Maternal glucocorticoid secretion mediates long-term effects of prenatal stress. Journal of Neuroscience 16 3943-3949.

Belelli D \& Lambert J 2005 Neurosteroids: endogenous regulators of the GABA(A) receptor. Nature Reviews. Neuroscience 6 565-575. (doi:10.1038/nrn1703)

Benediktsson R, Calder AA, Edwards CR \& Seckl JR 1997 Placental $11 \beta$-hydroxysteroid dehydrogenase: a key regulator of fetal glucocorticoid exposure. Clinical Endocrinology 46 161-166. (doi:10.1046/ j.1365-2265.1997.1230939.x)

Bjorkqvist K 2001 Social defeat as a stressor in humans. Physiology \& Behavior 73 435-442. (doi:10.1016/S0031-9384(01)00490-5)

Blanchard RJ, McKittrick CR \& Blanchard DC 2001 Animal models of social stress: effects on behavior and brain neurochemical systems. Physiology \& Behavior 73 261-271. (doi:10.1016/S0031-9384(01)00449-8)

Bosch OJ, Musch W, Bredewold R, Slattery DA \& Neumann ID 2007 Prenatal stress increases HPA axis activity and impairs maternal care in lactating female offspring: implications for postpartum mood disorder. Psychoneuroendocrinology 32 267-278. (doi:10.1016/j.psyneuen. 2006.12.012) 
Brunton PJ \& Russell JA 2010 Prenatal social stress in the rat programmes neuroendocrine and behavioural responses to stress in the adult offspring: sex specific effects. Journal of Neuroendocrinology 22 258-271. (doi:10.1111/j.1365-2826.2010.01969.x)

Brunton PJ, Meddle SL, Ma S, Ochedalski T, Douglas AJ \& Russell JA 2005 Endogenous opioids and attenuated hypothalamic-pituitary-adrenal axis responses to immune challenge in pregnant rats. Journal of Neuroscience 25 5117-5126. (doi:10.1523/JNEUROSCI.0866-05.2005)

Brunton PJ, Russell JA \& Douglas AJ 2008 Adaptive responses of the maternal hypothalamic-pituitary-adrenal axis during pregnancy and lactation. Journal of Neuroendocrinology 20 764-776. (doi:10.1111/ j.1365-2826.2008.01735.x)

Brunton PJ, McKay AJ, Ochedalski T, Piastowska A, Rebas E, Lachowicz A \& Russell JA 2009 Central opioid inhibition of neuroendocrine stress responses in pregnancy in the rat is induced by the neurosteroid allopregnanolone. Journal of Neuroscience 29 6449-6460. (doi:10.1523/JNEUROSCI.0708-09.2009)

Brunton PJ, Donadio MV \& Russell JA 2011 Sex differences in prenatally programmed anxiety behaviour in rats: differential corticotropinreleasing hormone receptor mRNA expression in the amygdaloid complex. Stress 14 634-643.

Brunton PJ, Sullivan KM, Kerrigan D, Russell JA, Seckl JR \& Drake AJ 2013 Sex-specific effects of prenatal stress on glucose homoeostasis and peripheral metabolism in rats. Journal of Endocrinology 217 161-173. (doi:10.1530/JOE-12-0540)

Buss C, Davis EP, Shahbaba B, Pruessner JC, Head K \& Sandman CA 2012 Maternal cortisol over the course of pregnancy and subsequent child amygdala and hippocampus volumes and affective problems. PNAS 109 E1312-E1319. (doi:10.1073/pnas.1201295109)

de Catanzaro D 1988 Effect of predator exposure upon early pregnancy in mice. Physiology \& Behavior 43 691-696. (doi:10.1016/0031-9384 (88)90365-4)

Champagne F \& Meaney MJ 2001 Like mother, like daughter: evidence for non-genomic transmission of parental behaviour and stress responsivity. Progress in Brain Research 133 287-302.

Chen CH, Klein DC \& Robinson JC 1974 Catechol-O-methyltransferase in rat placenta, human placenta and choriocarcinoma grown in culture. Journal of Reproduction and Fertility 39 407-410. (doi:10.1530/jrf.0. 0390407)

Chen CH, Klein DC \& Robinson JC 1976 Monoamine oxidase in rat placenta, human placenta, and cultured choriocarcinoma. Journal of Reproduction and Fertility 46 477-479. (doi:10.1530/jrf.0.0460477)

Chrousos GP, Torpy DJ \& Gold PW 1998 Interactions between the hypothalamic-pituitary-adrenal axis and the female reproductive system: clinical implications. Annals of Internal Medicine 129 229-240. (doi:10.7326/0003-4819-129-3-199808010-00012)

Claessens SE, Daskalakis NP, van der Veen R, Oitzl MS, de Kloet ER \& Champagne DL 2011 Development of individual differences in stress responsiveness: an overview of factors mediating the outcome of early life experiences. Psychopharmacology 214 141-154. (doi:10.1007/ s00213-010-2118-y)

Cratty MS, Ward HE, Johnson EA, Azzaro AJ \& Birkle DL 1995 Prenatal stress increases corticotropin-releasing factor (CRF) content and release in rat amygdala minces. Brain Research 675 297-302. (doi:10.1016/ 0006-8993(95)00087-7)

Davis EP, Glynn LM, Waffarn F \& Sandman CA 2011 Prenatal maternal stress programs infant stress regulation. Journal of Child Psychology and Psychiatry, and Allied Disciplines 52 119-129. (doi:10.1111/ j.1469-7610.2010.02314.x)

Diaz R, Brown RW \& Seckl JR 1998 Distinct ontogeny of glucocorticoid and mineralocorticoid receptor and $11 \beta$-hydroxysteroid dehydrogenase types I and II mRNAs in the fetal rat brain suggest a complex control of glucocorticoid actions. Journal of Neuroscience 18 2570-2580.

Douglas AJ, Brunton PJ, Bosch OJ, Russell JA \& Neumann ID 2003 Neuroendocrine responses to stress in mice: hyporesponsiveness in pregnancy and parturition. Endocrinology 144 5268-5276. (doi:10.1210/ en.2003-0461)

Dunn AJ \& Berridge CW 1990 Physiological and behavioral responses to corticotropin-releasing factor administration: is CRF a mediator of anxiety or stress responses? Brain Research Reviews 15 71-100. (doi:10.1016/0165-0173(90)90012-D)
Edinger KL \& Frye CA 2005 Testosterone's anti-anxiety and analgesic effects may be due in part to actions of its $5 \alpha$-reduced metabolites in the hippocampus. Psychoneuroendocrinology 30 418-430. (doi:10.1016/ j.psyneuen.2004.11.001)

Edwards LJ \& McMillen IC 2002 Impact of maternal undernutrition during the periconceptional period, fetal number, and fetal sex on the development of the hypothalamo-pituitary adrenal axis in sheep during late gestation. Biology of Reproduction 66 1562-1569. (doi:10.1095/ biolreprod66.5.1562)

Entringer S, Wust S, Kumsta R, Layes IM, Nelson EL, Hellhammer DH \& Wadhwa PD 2008 Prenatal psychosocial stress exposure is associated with insulin resistance in young adults. American Journal of Obstetrics and Gynecology 199 498.e1-498.e7. (doi:10.1016/j.ajog.2008.03.006)

Fan JM, Chen XQ, Jin H \& Du JZ 2009 Gestational hypoxia alone or combined with restraint sensitizes the hypothalamic-pituitary-adrenal axis and induces anxiety-like behavior in adult male rat offspring. Neuroscience 159 1363-1373. (doi:10.1016/j.neuroscience.2009.02.009)

Fride E \& Weinstock M 1984 The effects of prenatal exposure to predictable or unpredictable stress on early development in the rat. Developmental Psychobiology 17 651-660. (doi:10.1002/dev.420170607)

Fride E \& Weinstock M 1988 Prenatal stress increases anxiety related behavior and alters cerebral lateralization of dopamine activity. Life Sciences 42 1059-1065. (doi:10.1016/0024-3205(88)90561-9)

Frye CA \& Orecki ZA 2002 Prenatal stress alters reproductive responses of rats in behavioral estrus and paced mating of hormone-primed rats. Hormones and Behavior 42 472-483. (doi:10.1006/hbeh.2002.1834)

Frye CA \& Rhodes ME 2006 Infusions of $5 \alpha$-pregnan-3 $\alpha$-ol-20-one $(3 \alpha, 5 \alpha-$ THP) to the ventral tegmental area, but not the substantia nigra, enhance exploratory, anti-anxiety, social and sexual behaviours and concomitantly increase $3 \alpha, 5 \alpha$-THP concentrations in the hippocampus, diencephalon and cortex of ovariectomised oestrogen-primed rats. Journal of Neuroendocrinology 18 960-975. (doi:10.1111/j. 1365-2826.2006.01494.x)

Fujioka T, Fujioka A, Endoh H, Sakata Y, Furukawa S \& Nakamura S 2003 Materno-fetal coordination of stress-induced Fos expression in the hypothalamic paraventricular nucleus during pregnancy. Neuroscience 118 409-415. (doi:10.1016/S0306-4522(02)00781-9)

Gammie SC, Negron A, Newman SM \& Rhodes JS 2004 Corticotropinreleasing factor inhibits maternal aggression in mice. Behavioral Neuroscience 118 805-814. (doi:10.1037/0735-7044.118.4.805)

Gluckman PD \& Hanson MA 2004 Developmental origins of disease paradigm: a mechanistic and evolutionary perspective. Pediatric Research 56 311-317. (doi:10.1203/01.PDR.0000135998.08025.FB)

Gotz AA, Wolf M \& Stefanski V 2008 Psychosocial maternal stress during pregnancy: effects on reproduction for F0 and F1 generation laboratory rats. Physiology \& Behavior 93 1055-1060. (doi:10.1016/j.physbeh. 2008.01.009)

Gougeon A, Ecochard R \& Thalabard JC 1994 Age-related changes of the population of human ovarian follicles: increase in the disappearance rate of non-growing and early-growing follicles in aging women. Biology of Reproduction 50 653-663. (doi:10.1095/biolreprod50.3.653)

Gu W \& Jones CT 1986 The effect of elevation of maternal plasma catecholamines on the fetus and placenta of the pregnant sheep. Journal of Developmental Physiology 8 173-186.

Handa RJ, Burgess LH, Kerr JE \& O'Keefe JA 1994 Gonadal steroid hormone receptors and sex differences in the hypothalamo-pituitary-adrenal axis. Hormones and Behavior 28 464-476. (doi:10.1006/hbeh.1994.1044)

Henry C, Kabbaj M, Simon H, Le Moal M \& Maccari S 1994 Prenatal stress increases the hypothalamo-pituitary-adrenal axis response in young and adult rats. Journal of Neuroendocrinology 6 341-345. (doi:10.1111/j. 1365-2826.1994.tb00591.x)

Holson RR, Gough B, Sullivan P, Badger T \& Sheehan DM 1995 Prenatal dexamethasone or stress but not ACTH or corticosterone alter sexual behavior in male rats. Neurotoxicology and Teratology 17 393-401. (doi:10.1016/0892-0362(94)00074-N)

Hsu FC, Zhang GJ, Raol YS, Valentino RJ, Coulter DA \& Brooks-Kayal AR 2003 Repeated neonatal handling with maternal separation permanently alters hippocampal GABAA receptors and behavioral stress responses. PNAS 100 12213-12218. (doi:10.1073/pnas.2131679100)

Hunter EJ, Jones TA, Guise HJ, Penny RH \& Hoste S 2001 The relationship between tail biting in pigs, docking procedure and other management practices. Veterinary Journal 161 72-79. (doi:10.1053/tvjl.2000.0520) 
Igosheva N, Klimova O, Anishchenko T \& Glover V 2004 Prenatal stress alters cardiovascular responses in adult rats. Journal of Physiology $\mathbf{5 5 7}$ 273-285. (doi:10.1113/jphysiol.2003.056911)

Jarvis S, Moinard C, Robson SK, Baxter E, Ormandy E, Douglas AJ, Seckl JR, Russell JA \& Lawrence AB 2005 Programming the offspring of the pig by prenatal social stress: neuroendocrine activity and behaviour. Hormones and Behavior 49 68-80. (doi:10.1016/j.yhbeh.2005.05.004)

Kamel F \& Kubajak CL 1987 Modulation of gonadotropin secretion by corticosterone: interaction with gonadal steroids and mechanism of action. Endocrinology 121 561-568. (doi:10.1210/endo-121-2-561)

Kapoor A \& Matthews SG 2005 Short periods of prenatal stress affect growth, behaviour and hypothalamo-pituitary-adrenal axis activity in male guinea pig offspring. Journal of Physiology 566 967-977. (doi:10.1113/jphysiol.2005.090191)

Kapoor A \& Matthews SG 2011 Testosterone is involved in mediating the effects of prenatal stress in male guinea pig offspring. Journal of Physiology 589 755-766. (doi:10.1113/jphysiol.2010.200543)

Katz VL 2012 Work and work-related stress in pregnancy. Clinical Obstetrics and Gynecology 55 765-773. (doi:10.1097/GRF.0b013e318253b192)

Klampfl SM, Neumann ID \& Bosch OJ 2013 Reduced brain CRF activity is required for adequate maternal care and maternal aggression in lactating rats. European Journal of Neuroscience. In press. (doi:10.1111/ejn. 12274)

Koenig JI, Elmer GI, Shepard PD, Lee PR, Mayo C, Joy B, Hercher E \& Brady DL 2005 Prenatal exposure to a repeated variable stress paradigm elicits behavioral and neuroendocrinological changes in the adult offspring: potential relevance to schizophrenia. Behavioural Brain Research 156 251-261. (doi:10.1016/j.bbr.2004.05.030)

Laplante DP, Brunet A, Schmitz N, Ciampi A \& King S 2008 Project Ice Storm: prenatal maternal stress affects cognitive and linguistic functioning in 5 1/2-year-old children. Journal of the American Academy of Child and Adolescent Psychiatry 47 1063-1072. (doi:10.1097/CHI. 0b013e31817eec80)

Laszlo KD, Liu XQ, Svensson T, Wikstrom AK, Li J, Olsen J, Obel C, Vestergaard M \& Cnattingius S 2013 Psychosocial stress related to the loss of a close relative the year before or during pregnancy and risk of preeclampsia. Hypertension 62 183-189. (doi:10.1161/ HYPERTENSIONAHA.111.00550)

Lee PR, Brady DL, Shapiro RA, Dorsa DM \& Koenig JI 2007 Prenatal stress generates deficits in rat social behavior: reversal by oxytocin. Brain Research 1156 152-167. (doi:10.1016/j.brainres.2007.04.042)

Lee BE, Ha M, Park H, Hong YC, Kim Y, Kim YJ \& Ha EH 2011 Psychosocial work stress during pregnancy and birthweight. Paediatric and Perinatal Epidemiology 25 246-254. (doi:10.1111/j.1365-3016.2010.01177.x)

Lemaire V, KoehI M, Le Moal M \& Abrous DN 2000 Prenatal stress produces learning deficits associated with an inhibition of neurogenesis in the hippocampus. PNAS 97 11032-11037. (doi:10.1073/pnas.97.20.11032)

Levine S 1967 Maternal and environmental influences on the adrenocortical response to stress in weanling rats. Science 156 258-260. (doi:10.1126/science.156.3772.258)

Levitt NS, Lambert EV, Woods D, Hales CN, Andrew R \& Seckl JR 2000 Impaired glucose tolerance and elevated blood pressure in low birth weight, nonobese, young South African adults: early programming of cortisol axis. Journal of Clinical Endocrinology and Metabolism 85 4611-4618. (doi:10.1210/jc.85.12.4611)

Lingas RI \& Matthews SG 2001 A short period of maternal nutrient restriction in late gestation modifies pituitary-adrenal function in adult guinea pig offspring. Neuroendocrinology 73 302-311. (doi:10.1159/ 000054647)

Liu D, Diorio J, Tannenbaum B, Caldji C, Francis D, Freedman A, Sharma S, Pearson D, Plotsky PM \& Meaney MJ 1997 Maternal care, hippocampal glucocorticoid receptors, and hypothalamic-pituitary-adrenal responses to stress. Science 277 1659-1662. (doi:10.1126/science.277.5332. 1659)

Lund TD, Hinds LR \& Handa RJ 2006 The androgen $5 \alpha$-dihydrotestosterone and its metabolite $5 \alpha$-androstan- $3 \beta, 17 \beta$-diol inhibit the hypothalamopituitary-adrenal response to stress by acting through estrogen receptor $\beta$-expressing neurons in the hypothalamus. Journal of Neuroscience 26 1448-1456. (doi:10.1523/JNEUROSCI.3777-05.2006)

Mahenge B, Likindikoki S, Stockl H \& Mbwambo J 2013 Intimate partner violence during pregnancy and associated mental health symptoms among pregnant women in Tanzania: a cross-sectional study. BJOG: an International Journal of Obstetrics and Gynaecology 120 940-947. (doi:10.1111/1471-0528.12185)

Makino S, Gold PW \& Schulkin J 1994 Corticosterone effects on corticotropin-releasing hormone mRNA in the central nucleus of the amygdala and the parvocellular region of the paraventricular nucleus of the hypothalamus. Brain Research 640 105-112. (doi:10.1016/ 0006-8993(94)91862-7)

Mason SP, Jarvis S \& Lawrence AB 2003 Individual differences in responses of piglets to weaning at different ages. Applied Animal Behaviour Science 80 117-132. (doi:10.1016/S0168-1591(02)00209-5)

McCormick CM, Smythe JW, Sharma S \& Meaney MJ 1995 Sex-specific effects of prenatal stress on hypothalamic-pituitary-adrenal responses to stress and brain glucocorticoid receptor density in adult rats. Developmental Brain Research 84 55-61. (doi:10.1016/01653806(94)00153-Q)

McEwen BS 2008 Central effects of stress hormones in health and disease: understanding the protective and damaging effects of stress and stress mediators. European Journal of Pharmacology 583 174-185. (doi:10.1016/j.ejphar.2007.11.071)

Meaney MJ, Aitken DH, Viau V, Sharma S \& Sarrieau A 1989 Neonatal handling alters adrenocortical negative feedback sensitivity and hippocampal type II glucocorticoid receptor binding in the rat. Neuroendocrinology 50 597-604. (doi:10.1159/000125287)

Meaney MJ, Szyf M \& Seckl JR 2007 Epigenetic mechanisms of perinatal programming of hypothalamic-pituitary-adrenal function and health. Trends in Molecular Medicine 13 269-277. (doi:10.1016/j.molmed. 2007.05.003)

Moore CL 1982 Maternal behavior of rats is affected by hormonal condition of pups. Journal of Comparative and Physiological Psychology 96 123-129. (doi:10.1037/h0077866)

Moore CL 1984 Maternal contributions to the development of masculine sexual behavior in laboratory rats. Developmental Psychobiology 17 347-356. (doi:10.1002/dev.420170403)

Moore CL \& Power KL 1986 Prenatal stress affects mother-infant interaction in Norway rats. Developmental Psychobiology 19 235-245. (doi:10.1002/dev.420190309)

Mueller BR \& Bale TL 2008 Sex-specific programming of offspring emotionality after stress early in pregnancy. Journal of Neuroscience 28 9055-9065. (doi:10.1523/JNEUROSCI.1424-08.2008)

Neumann ID, Johnstone HA, Hatzinger M, Liebsch G, Shipston M, Russell JA, Landgraf R \& Douglas AJ 1998 Attenuated neuroendocrine responses to emotional and physical stressors in pregnant rats involve adenohypophysial changes. Journal of Physiology 508 289-300. (doi:10.1111/j.1469-7793.1998.289br.x)

Nilsson C, Larsson BM, Jennische E, Eriksson E, Bjorntorp P, York DA \& Holmang A 2001 Maternal endotoxemia results in obesity and insulin resistance in adult male offspring. Endocrinology 142 2622-2630. (doi:10.1210/en.142.6.2622)

Nunez H, Ruiz S, Soto-Moyano R, Navarrete M, Valladares L, White A \& Perez H 2008 Fetal undernutrition induces overexpression of $\mathrm{CRH}$ mRNA and $\mathrm{CRH}$ protein in hypothalamus and increases $\mathrm{CRH}$ and corticosterone in plasma during postnatal life in the rat. Neuroscience Letters 448 115-119. (doi:10.1016/j.neulet.2008.10.014)

Ohkawa T, Rohde W, Takeshita S, Dorner G, Arai K \& Okinaga S 1991 Effect of an acute maternal stress on the fetal hypothalamopituitary-adrenal system in late gestational life of the rat. Experimental and Clinical Endocrinology 98 123-129. (doi:10.1055/ s-0029-1211108)

Otten W, Kanitz E, Couret D, Veissier I, Prunier A \& Merlot E 2010 Maternal social stress during late pregnancy affects hypothalamicpituitary-adrenal function and brain neurotransmitter systems in pig offspring. Domestic Animal Endocrinology 38 146-156. (doi:10.1016/ j.domaniend.2009.09.002)

Palombo DJ, Nowoslawski M \& Fleming AS 2010 Motherless rats show deficits in maternal behavior towards fostered pups. Developmental Psychobiology 52 142-148. (doi:10.1002/dev.20422)

Paris J] \& Frye CA 2011 Juvenile offspring of rats exposed to restraint stress in late gestation have impaired cognitive performance and dysregulated progestogen formation. Stress 14 23-32. (doi:10.3109/10253890.2010. 512375) 
Paris JJ, Brunton PJ, Russell JA \& Frye CA 2011 Immune stress in late pregnant rats decreases length of gestation, fecundity, and alters later cognitive and affective behaviour of surviving pre-adolescent offspring. Stress 14 652-664. (doi:10.3109/10253890.2011.628719)

Parker VJ, Menzies JR \& Douglas AJ 2011 Differential changes in the hypothalamo-pituitary-adrenal axis and prolactin responses to stress in early pregnant mice. Journal of Neuroendocrinology 23 1066-1078. (doi:10.1111/j.1365-2826.2011.02204.x)

Patchev VK, Shoaib M, Holsboer F \& Almeida OF 1994 The neurosteroid tetrahydroprogesterone counteracts corticotropin-releasing hormoneinduced anxiety and alters the release and gene expression of corticotropin-releasing hormone in the rat hypothalamus. Neuroscience 62 265-271. (doi:10.1016/0306-4522(94)90330-1)

Patchev VK, Hassan AH, Holsboer F \& Almeida OF 1996 The neurosteroid tetrahydroprogesterone attenuates the endocrine response to stress and exerts glucocorticoid-like effects on vasopressin gene transcription in the rat hypothalamus. Neuropsychopharmacology 15 533-540. (doi:10.1016/ S0893-133X(96)00096-6)

Patin V, Lordi B, Vincent A \& Caston J 2005 Effects of prenatal stress on anxiety and social interactions in adult rats. Brain Research. Developmental Brain Research 160 265-274. (doi:10.1016/j.devbrainres.2005.09.010)

Pedersen CA, Caldwell JD, McGuire M \& Evans DL 1991 Corticotropinreleasing hormone inhibits maternal behavior and induces pup-killing. Life Sciences 48 1537-1546. (doi:10.1016/0024-3205(91)90278-J)

Phillips DIW, Barker DJP, Fall CHD, Seckl JR, Whorwood CB, Wood PJ \& Walker BR 1998 Elevated plasma cortisol concentrations: an explanation for the relationship between low birth weight and adult cardiovascular risk factors. Journal of Clinical Endocrinology and Metabolism 83 757-760. (doi:10.1210/jc.83.3.757)

Poltyrev T, Keshet GI, Kay G \& Weinstock M 1996 Role of experimental conditions in determining differences in exploratory behavior of prenatally stressed rats. Developmental Psychobiology 29 453-462. (doi:10.1002/ (SICl)1098-2302(199607)29:5<453::AID-DEV4> 3.0.CO;2-N)

Pratt NC \& Lisk RD 1991 Role of progesterone in mediating stress-related litter deficits in the golden hamster (Mesocricetus auratus). Journal of Reproduction and Fertility 92 139-146. (doi:10.1530/jrf.0.0920139)

Reynolds RM 2013 Glucocorticoid excess and the developmental origins of disease: two decades of testing the hypothesis - 2012 Curt Richter Award Winner. Psychoneuroendocrinology 38 1-11. (doi:10.1016/j.psyneuen. 2012.08.012)

Rivier C, Rivier J \& Vale W 1986 Stress-induced inhibition of reproductive functions: role of endogenous corticotropin-releasing factor. Science 231 607-609. (doi:10.1126/science.3003907)

Roelfsema V, Gunn AJ, Fraser M, Quaedackers JS \& Bennet L 2005 Cortisol and $\mathrm{ACTH}$ responses to severe asphyxia in preterm fetal sheep. Experimental Physiology 90 545-555. (doi:10.1113/expphysiol.2005. 030320)

Russell JA, Douglas AJ \& Brunton PJ 2008 Reduced hypothalamo-pituitaryadrenal axis stress responses in late pregnancy: central opioid inhibition and noradrenergic mechanisms. Annals of the New York Academy of Sciences 1148 428-438. (doi:10.1196/annals.1410.032)

Rutherford KM, Robson SK, Donald RD, Jarvis S, Sandercock DA, Scott EM, Nolan AM \& Lawrence AB 2009 Pre-natal stress amplifies the immediate behavioural responses to acute pain in piglets. Biology Letters $\mathbf{5}$ 452-454. (doi:10.1098/rsbl.2009.0175)

Sandercock DA, Gibson IF, Rutherford KM, Donald RD, Lawrence AB, Brash HM, Scott EM \& Nolan AM 2011 The impact of prenatal stress on basal nociception and evoked responses to tail-docking and inflammatory challenge in juvenile pigs. Physiology \& Behavior 104 728-737. (doi:10.1016/j.physbeh.2011.07.018)

Sandman CA, Wadhwa PD, Chicz-DeMet A, Dunkel-Schetter C \& Porto M 1997 Maternal stress, HPA activity, and fetal/infant outcome. Annals of the New York Academy of Sciences 814 266-275. (doi:10.1111/j. 1749-6632.1997.tb46162.x)

Sandman CA, Davis EP, Buss C \& Glynn LM 2012 Exposure to prenatal psychobiological stress exerts programming influences on the mother and her fetus. Neuroendocrinology 95 7-21. (doi:10.1159/000327017)

Schulkin J, Gold PW \& McEwen BS 1998 Induction of corticotropinreleasing hormone gene expression by glucocorticoids: implication for understanding the states of fear and anxiety and allostatic load. Psychoneuroendocrinology 23 219-243. (doi:10.1016/S0306-4530(97) 00099-1)
Seckl JR \& Holmes MC 2007 Mechanisms of disease: glucocorticoids, their placental metabolism and fetal 'programming' of adult pathophysiology. Nature Clinical Practice. Endocrinology \& Metabolism 3 479-488. (doi:10.1038/ncpendmet0515)

Smith JW, Seckl JR, Evans AT, Costall B \& Smythe JW 2004 Gestational stress induces post-partum depression-like behaviour and alters maternal care in rats. Psychoneuroendocrinology 29 227-244. (doi:10.1016/ S0306-4530(03)00025-8)

Smythe JW, McCormick CM \& Meaney MJ 1996 Median eminence corticotrophin-releasing hormone content following prenatal stress and neonatal handling. Brain Research Bulletin 40 195-199. (doi:10.1016/ 0361-9230(95)02146-9)

Sodha RJ, Proegler M \& Schneider H 1984 Transfer and metabolism of norepinephrine studied from maternal-to-fetal and fetal-to-maternal sides in the in vitro perfused human placental lobe. American Journal of Obstetrics and Gynecology 148 474-481.

Takahashi LK \& Kalin NH 1991 Early developmental and temporal characteristics of stress-induced secretion of pituitary-adrenal hormones in prenatally stressed rat pups. Brain Research 558 75-78. (doi:10.1016/ 0006-8993(91)90715-8)

Tamashiro KL, Terrillion CE, Hyun J, Koenig JI \& Moran TH 2009 Prenatal stress or high-fat diet increases susceptibility to diet-induced obesity in rat offspring. Diabetes 58 1116-1125. (doi:10.2337/db081129)

Vaha-Eskeli KK, Erkkola RU, Scheinin M \& Seppanen A 1992 Effects of short-term thermal stress on plasma catecholamine concentrations and plasma renin activity in pregnant and nonpregnant women. American Journal of Obstetrics and Gynecology 167 785-789. (doi:10.1016/ S0002-9378(11)91590-7)

Valladares E, Pena R, Ellsberg M, Persson LA \& Hogberg U 2009 Neuroendocrine response to violence during pregnancy - impact on duration of pregnancy and fetal growth. Acta Obstetricia et Gynecologica Scandinavica 88 818-823. (doi:10.1080/00016340903015321)

Vallee M, Mayo W, Dellu F, Le Moal M, Simon H \& Maccari S 1997 Prenatal stress induces high anxiety and postnatal handling induces low anxiety in adult offspring: correlation with stress-induced corticosterone secretion. Journal of Neuroscience 17 2626-2636.

Wakshlak A \& Weinstock M 1990 Neonatal handling reverses behavioral abnormalities induced in rats by prenatal stress. Physiology \& Behavior 48 289-292. (doi:10.1016/0031-9384(90)90315-U)

Walf AA \& Frye CA 2012 Gestational or acute restraint in adulthood reduces levels of $5 \alpha$-reduced testosterone metabolites in the hippocampus and produces behavioral inhibition of adult male rats. Frontiers in Cellular Neuroscience 6 40. (doi:10.3389/fncel.2012.00040)

Wang CT, Shui HA, Huang RL, Tai MY, Peng MT \& Tsai YF 2006 Sexual motivation is demasculinized, but not feminized, in prenatally stressed male rats. Neuroscience 138 357-364. (doi:10.1016/j. neuroscience.2005.11.026)

Wang X, Meng FS, Liu ZY, Fan JM, Hao K, Chen XQ \& Du JZ 2013 Gestational hypoxia induces sex-differential methylation of Crhr1 linked to anxiety-like behavior. Molecular Neurobiology. In press. (doi:10. 1007/s12035-013-8444-4)

Ward IL 1972 Prenatal stress feminizes and demasculinizes the behavior of males. Science 175 82-84. (doi:10.1126/science.175.4017.82)

Ward IL \& Weisz J 1980 Maternal stress alters plasma testosterone in fetal males. Science 207 328-329. (doi:10.1126/science.7188648)

Ward IL \& Weisz J 1984 Differential effects of maternal stress on circulating levels of corticosterone, progesterone, and testosterone in male and female rat fetuses and their mothers. Endocrinology 114 1635-1644. (doi:10.1210/endo-114-5-1635)

Ward HE, Johnson EA, Salm AK \& Birkle DL 2000 Effects of prenatal stress on defensive withdrawal behavior and corticotropin releasing factor systems in rat brain. Physiology \& Behavior 70 359-366. (doi:10.1016/ S0031-9384(00)00270-5)

Weaver IC, Cervoni N, Champagne FA, D'Alessio AC, Sharma S, Seckl JR, Dymov S, Szyf M \& Meaney MJ 2004 Epigenetic programming by maternal behavior. Nature Neuroscience 7 847-854. (doi:10.1038/ nn1276)

Weinstock M, Matlina E, Maor GI, Rosen H \& McEwen BS 1992 Prenatal stress selectivity alters the reactivity of the hypothalamic-pituitary adrenal system in the female rat. Brain Research 595 195-200. (doi:10.1016/0006-8993 (92)91049-K) 
Welberg LA \& Seckl JR 2001 Prenatal stress, glucocorticoids and the programming of the brain. Journal of Neuroendocrinology 13 113-128. (doi:10.1111/j.1365-2826.2001.00601.x)

Welberg LA, Seckl JR \& Holmes MC 2001 Prenatal glucocorticoid programming of brain corticosteroid receptors and corticotrophin-releasing hormone: possible implications for behaviour. Neuroscience 104 71-79. (doi:10.1016/S0306-4522(01)00065-3)

Welberg LA, Thrivikraman KV \& Plotsky PM 2005 Chronic maternal stress inhibits the capacity to up-regulate placental $11 \beta$-hydroxysteroid dehydrogenase type 2 activity. Journal of Endocrinology 186 R7-R12. (doi:10.1677/joe.1.06374)

Zagron G \& Weinstock M 2006 Maternal adrenal hormone secretion mediates behavioural alterations induced by prenatal stress in male and female rats. Behavioural Brain Research 175 323-328. (doi:10.1016/ j.bbr.2006.09.003)

Zielinski WJ, Vandenbergh JG \& Montano MM 1991 Effects of social stress and intrauterine position on sexual phenotype in wild-type house mice (Mus musculus). Physiology \& Behavior 49 117-123. (doi:10.1016/ 0031-9384(91)90241-F)
Zimmerberg B \& Blaskey LG 1998 Prenatal stress effects are partially ameliorated by prenatal administration of the neurosteroid allopregnanolone. Pharmacology, Biochemistry, and Behavior 59 819-827. (doi:10.1016/S0091-3057(97)00540-6)

Zohar I \& Weinstock M 2011 Differential effect of prenatal stress on the expression of corticotrophin-releasing hormone and its receptors in the hypothalamus and amygdala in male and female rats. Journal of Neuroendocrinology 23 320-328. (doi:10.1111/j.1365-2826.2011. 02117.x)

Zuena AR, Mairesse J, Casolini P, Cinque C, Alema GS, Morley-Fletcher S, Chiodi V, Spagnoli LG, Gradini R, Catalani A et al. 2008 Prenatal restraint stress generates two distinct behavioral and neurochemical profiles in male and female rats. PLoS ONE 3 e2170. (doi:10.1371/ journal.pone.0002170)

Received 16 June 2013

First decision 11 July 2013

Accepted 30 July 2013 